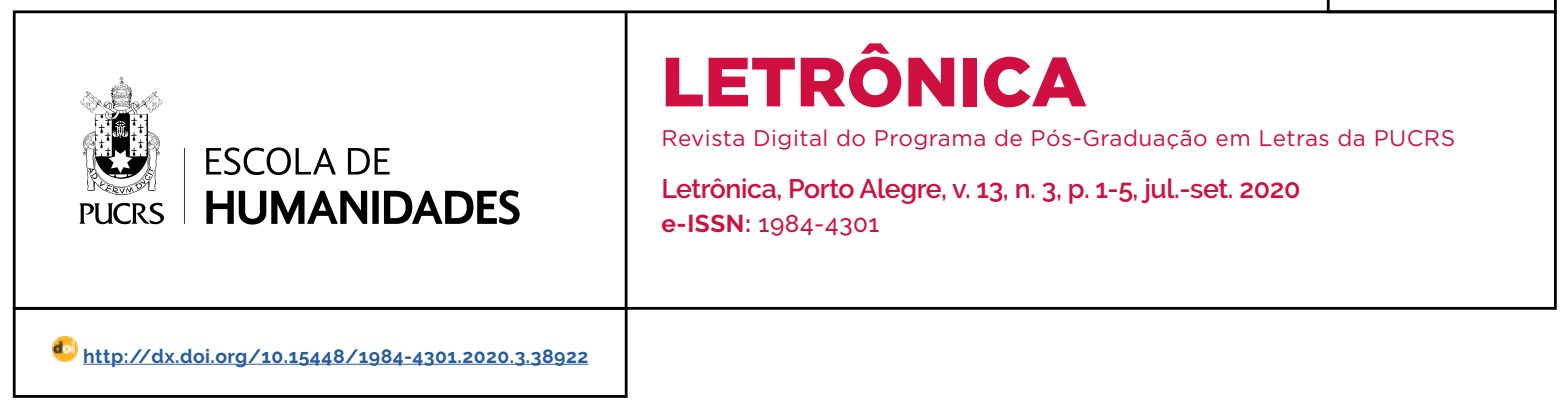

EDITORIAL

\title{
Representações do Brasil nas literaturas em língua portuguesa e nas literaturas em língua espanhola
}

\author{
Brazilian portrayals in Portuguese and Spanish language and literature
}

\author{
Maria Eunice Moreira ${ }^{1}$ \\ orcid.org/0000-0003-1019-8519 \\ maria.eunice@pucrs.br
}

\section{Paulo Ricardo Kralik \\ Angelini ${ }^{1}$ \\ orcid.org/0000-0002-7096-0109 \\ paulo.angelini@pucrs.br}

\section{Ascensión Rivas \\ Hernández ${ }^{2}$ \\ orcid.org/0000-0002-7069-3311 sisina@usal.es}

\section{Marcela Croce ${ }^{3}$}

orcid.org/0000-0001-6625-1281 marcela.croce@gmail.com mcroce@filo.uba.ar-

\section{Ana Cristina Steffen ${ }^{1}$}

orcid.org/0000-0003-2243-7679 ana.steffen@acad.pucrs.br

Recebido em: 19/6/2020. Aprovado em: 25/6/2020. Publicado em: 30/10/2020.

\section{(c) (1)}

Artigo está licenciado sob forma de uma licença Creative Commons Atribuição 4.0 Internacional.
Nascida no bojo da literatura portuguesa, em virtude das condições de ordem politica e social decorrentes da situação colonial, a literatura brasileira desenvolveu-se, especialmente a partir do século XIX, buscando definir uma identidade própria, que a tornasse original e diferente em relação ao tronco de sua origem. Nessa direção, privilegiou sobretudo o espaço do território brasileiro como um elemento identificador dessa diferença. Tematizar a natureza, a história da jovem nação, seus habitantes e costumes constitui a preocupação dos primeiros escritores brasileiros, em suas diferentes formas de expressão, seja a poesia, o teatro, o romance, a novela. O espaço nacional tornou-se assim a personagem mais importante na literatura que o Brasil passou a produzir e transformou-se no decorrer dos tempos no tópico identificador de "brasilidade".

De alguma forma, essa natureza exuberante e tão diversificada, da selva, dos morros, da praia, sobrevive como elemento recorrente quando se pensa no Brasil. Eduardo Lourenço, aliás, um dos intelectuais portugueses que mais problematiza as relações culturais entre Portugal e Brasil, afirma, por exemplo, ser inequivoco o fato de os portugueses pensarem muito mais no Brasil (do que o contrário); todavia, a imagem que possuem do país é, em geral, "extravagante", uma "alucinação" (LOURENÇO, 2001). O Brasil paradisíaco, do sol, do samba, do carnaval, do povo alegre e festivo, mas pouco sério, parece sobreviver em muitas narrativas da contemporaneidade.

De outra parte, inserido no continente americano, partilhando com as antigas colônias da Espanha fronteiras e costumes, o Brasil não manteve relações literárias muito significativas com essas novas nações. Para os sul-americanos, o espaço brasileiro era exótico e, de certo modo, como disse José Mármol, o exilado argentino que viveu no Brasil na metade do século XIX, punha-lhe medo "el sol de acá" (SARMIENTO, 1849). Novamente, o espaço era o elemento em torno do qual se avaliava o país e a sua produção artística.

\footnotetext{
Pontificia Universidade Católica do Rio Grande do Sul (PUCRS), Porto Alegre, RS, Brasil.

Universidade de Salamanca, Salamanca, Espanha.

Universidade de Buenos Aires (UBA), Buenos Aires, Argentina.
} 
Entre fascínio e medo, interesse e repulsa, o Brasil foi sendo definido pela literatura como um espaço heterogêneo, onde convergem os mais diferentes recursos - humanos, naturais, politicos - enfim, um espaço múltiplo que a literatura representa em seus variados gêneros.

Este número da revista Letrônica reúne um conjunto de ensaios que proporcionam uma leitura atualizada sobre a representação do Brasil nas literaturas em língua portuguesa e nas literaturas em língua espanhola. O olhar sobre essas produções cruza o tempo, volta ao passado ou localiza-se no presente, investigando e analisando a produção brasileira sob perspectivas teóricas variadas, gêneros múltiplos (romance, novela, drama, poesia, cartas, crônicas) para compor um volume tão multifacetado e variado quanto variadas são as faces desse país chamado Brasil.

É importante destacar que, entre os 17 trabalhos que compõem esse número, a maior parte é dedicada à literatura brasileira. Dentre esses, pouco mais da metade se debruça sobre obras do século $X X I$, e o restante sobre obras da primeira metade do século $X X$. Duas exceções são os ensaios que abordam Machado de Assis: "As ideias dentro do lugar: liberalismo, escravidão e cinismo" e "As vicissitudes da pseudoatividade na mentalidade industrial de Inácio e Benedito: uma proposta de leitura do conto 'Evolução' (1884), de Machado de Assis, sob o viés do materialismo lacaniano", de autoria de Marcelo Burmann dos Santos, e de Rafael Lucas Santos da Silva e Marisa Corrêa Silva, respectivamente. O primeiro artigo discute a maneira como o autor retratou o escravismo em Memórias Póstumas de Brás Cubas (1881), a partir da estetização da violência proporcionada pela prática da escravidão na perspectiva das oligarquias do país - ironizadas na obra de Machado de Assis. Além disso, também se discute de que forma é retratada a adoção de ideias liberais pela elite nacional. O segundo texto propõe uma leitura para o conto "Evolução", a partir do materialismo de Jacques Lacan e da categoria de pseudoatividade de filósofo Slavoj Žižek, principalmente, objetivando demonstrar de que maneira se constrói um esquema estético reflexivo sobre as contradições presentes na formação social brasileira.
Dentre os artigos voltados a obras da primeira metade do século $X X$, há dois dirigidos ao maranhense Graça Aranha. Em "Estética Artenovista, Linguagem Germanista: incursões pela Chanaan de Graça Aranha", de Andrea Ramon Ruocco, é trazida uma proposta em que o objetivo é desvelar as especificidades do romance indicado no título - publicado em 1902 -, para além do seu rótulo de "pré-modernista". Exemplos dessas peculiaridades seriam o uso de uma linguagem germanista e a possibilidade de uma estética artenovista. Já "Uma filosofia para o Brasil: a identidade nacional brasileira em A estética da vida", de Débora Priscila Graeff, visa analisar a representação da identidade nacional brasileira presente no conjunto de ensaios do autor reunido em $A$ estética da vida (1921), livro no qual Graça Aranha preocupou-se em definir o que significava ser brasileiro.

Em "O Momento Literário, de João Do Rio, e o espírito das polêmicas", Silvia Maria Azevedo volta-se à obra O momento literário (1909), em que está reunida uma série de reportagens com escritores da literatura brasileira, feitas pelo cronista carioca. Esse estudo tem como objetivo identificar, por meio da recuperação dos depoimentos presentes no livro, a polêmica como expressão constitutiva da república das letras no Brasil. Na sequência, "'Não vim no mundo para ser pedra': o herói inútil em Macunaíma", de Keissy Guariento Carvelli, propõe uma abordagem sobre o caráter "inútil" do personagem homônimo ao romance de Mário de Andrade, publicado em 1928. Por meio da investigação desse herói, se procura observar como ele, ao passar por transformações em três momentos decisivos da narrativa, transforma também seu modo de existir, fundando-se como um "herói inútil". Por último, o artigo "A literatura brasileira vista de longe", de Bruna Carolina de Almeida Salles, estuda a difusão da literatura brasileira modernista na Europa, bem como sua repercussão no meio acadêmico, principalmente em Portugal. Esse trabalho, ainda, expõe a influência de tal literatura sobre escritores cabo-verdianos do início do século XX.

Dentre os artigos dedicados à literatura brasileira do século XXI, dois deles apresentam estudos sobre peças teatrais. O primeiro é "História, historiografia e historicidade: a morte de 
Lima Barreto", de Eneida Leal Cunha, no qual são explorados os efeitos da encenação - no espetáculo Traga-me a cabeça de Lima Barreto! (2017) - para iluminar os sombreamentos presentes nas décadas iniciais do século XX no País, seja na história nacional, seja na historiografia literária. Com isso, também se expõe o racismo como parte da estrutura da sociedade moderna brasileira, bem como seus efeitos na vida e obra de Lima Barreto. O segundo artigo, "Imaginando a nação no teatro: criação, escrita e encenação de BR-3, do Teatro da Vertigem e Bernardo CarvaIho", de autoria de Carolina Montebelo Barcelos, analisa como foi imaginada uma concepção de nação brasileira e o que se compreende como identidade nacional na peça $B R-3$, montada em 2006, assinada por Bernardo Carvalho e encenada pela companhia Teatro da Vertigem.

O artigo seguinte realiza uma proposta de leitura na qual raça e gênero são colocados de maneira interseccional. Em "Gênero e raça em Xica da Silva: a cinderela negra, de Ana Miranda", texto dedicado à obra de Ana Miranda, publicada em 2016. Amanda da Silva Oliveira analisa o espaço ocupado pelas mulheres nas produções literárias feministas da atualidade, além de defender que o registro da história de personagens femininas proporciona releituras da história oficial. O último trabalho a abordar a literatura brasileira do século $X X I$, por fim, è "A periferia na literatura brasileira contemporânea, um exercício de alteridade", de Maria Tereza Amodeo. Nesse texto, é analisada a temática da realidade marginal e periférica brasileira, tomando por referência os contos "O Ônibus Branco" (2006), de Ferréz, "Nossa Rainha" (2005), de Marcelino Freire, "Balaio" (2015), de Marçal Aquino, e o poema "Poética da desistência" (2017), de Dinha (pseudônimo de Maria Nilda de Carvalho Mota).

A literatura brasileira é objeto de estudo no ensaio "Historia y canon literario: una pesadilla que aprendimos a repetir Boca do Inferno y Agosto desde la vigilancia de Respiración artificial", de autoria de Marcela Croce. Nesse texto, a investigadora argentina propõe uma leitura comparativa entre Boca do Inferno (1989), de Ana Miranda, e Agosto (1990), de Rubem Fonseca, considerados enquanto romances históricos que se valem de um fato do passado para intervir no presente. Porém, esse estudo, conforme anuncia seu título, além da leitura dos dois romances brasileiros, também traz para discussão o romance do argentino Ricardo Piglia, Respiração Artificial (1980), responsável pela "vigilância epistemológica" que fornece a base para a ligação entre as obras de Miranda e Fonseca. Além desse estudo, há um segundo que se ocupa da literatura latino-americana: "A miopia como metáfora para o intelectual latino-americano: Vargas Llosa lê Os sertões, de Euclides da Cunha", de autoria de Pedro Borges Pimenta Júnior e Elcio Lucas de Oliveira. Também de viés comparatista, o ensaio aborda duas obras antológicas, A guerra do fim do mundo (1981), de Vargas Llosa, e Os sertões (1902), de Euclides da Cunha. O objetivo é discutir como Llosa trabalhou a metáfora da miopia para representar os intelectuais latino-americanos que, a exemplo de Cunha, romperam com as representações estereotipadas sobre o sertão brasileiro.

Os dois textos seguintes são dedicados a obras de origem espanhola. O primeiro deles é "A Petrópolis imperial sob o sombreiro da espanhola Carmen Oliver", de autoria de Katia Aily F. de Camargo e Lucía Molina. Tendo como base - paradigma da descrição na tradução etnográfica, investiga o relato Viaje poético a Petrópolis (1872), de Carmen Oliver de Gelabert. Com isso, também se esboça uma representação do Brasil por meio da análise dos "culturemas", conforme o conceito de Molina. O segundo trabalho é "El Brasil restituido: o Brasil como espaço de glória no imaginário espanhol", de Wagner Monteiro e Ana Karla Carvalho Canarinos. Nesse artigo, é feita uma análise da peça teatral El Brasil restituido (1625), de autoria de Félix Lope de Vega y Carpio, propondo uma relação entre o domínio espanhol no Brasil e o imaginário acerca desse na península ibérica seiscentista a partir de estereótipos como o da antropofagia. Ademais, também é demonstrado como o judaísmo, no contexto ibero-americano, é incorporado na obra de Lope de Vega, bem como de que forma se apresenta o componente indígena. 
Dois artigos, por fim, são dedicados à literatura portuguesa. O primeiro deles é "Criar um Brasil ou ser criado por ele: leituras do país sob a perspectiva de António Vieira em A Eternidade e o desejo, de Inês Pedrosa", de Marcelo Franz, em que a proposta é analisar o diálogo estabelecido entre o romance do título - publicado em 2007 - e os elementos formais de romances de ambiente e de narrativas de viagem. Tal discussão, ainda, estabelece uma ligação sobre o Brasil enquanto território físico, cultural e afetivo, conforme ele surge na viagem descrita pela obra. No segundo estudo, "Imigração na literatura: escritores portugueses e a vida no Brasil", de Mario Luis Grangeia, são debatidas as aproximações e os distanciamentos no imaginário acerca da imigração portuguesa no Brasil a partir de livros de três portugueses que viveram no País: Gomes de Amorim, Ferreira de Castro e Miguel Torga. Tal imaginário ainda é contrastado com o de escritores que não imigraram, e também, com as concepções de Eduardo Lourenço e Vitorino Nemésio, que aqui viveram, e escreveram sobre o Brasil.

Visto sob ângulos e perspectivas diferenciadas, em temporalidades mais distantes ou mais próximas de nós, o conjunto de temas, autores e obras tratados neste volume de Letrônica possibilita "ver" o Brasil como um país múltiplo e heterogêneo. Apesar de "ser bonito por natureza", o país mostra seus problemas e suas feridas, estimulando a análise de obras e de autores que transitem por sua realidade complexa e ainda aberta a novas interpretações.

\section{Referências}

AMANTE, Adriana. O estrangeiro, muito romântico - a literatura dos escritores românticos argentinos exilados no Brasil. In: SANTOS, Luís Alberto Brandão; PEREIRA, Maria Antonieta (org.). Trocas culturais na América Latina. Belo Horizonte: Pós-Lit/FALE/UFMG; Nelam/FALE/ UFMG, 2000. p. 151-158.

LOURENÇO, Eduardo. A nau de Ícaro e Imagem e miragem da lusofonia. São Paulo: Companhia das Letras, 2001.

\section{Maria Eunice Moreira}

Doutora em Teoria Literária pela Pontifícia Universidade Católica do Rio Grande do Sul (PUCRS), em Porto Alegre, RS, Brasil; é professora titular da Pontificia Universidade Católica do Rio Grande do Sul (PUCRS), em Porto Alegre, RS, Brasil.

\section{Paulo Ricardo Kralik Angelini}

Doutor em Literaturas em Língua Portuguesa pela Universidade Federal do Rio Grande do Sul (UFRGS), em Porto Alegre, RS, Brasil; professor adjunto da Pontificia Universidade Católica do Rio Grande do Sul (PUCRS), em Porto Alegre, RS, Brasil.

\section{Ascensión Rivas Hernández}

Doutora em Filologia Hispânica pela Universidade de Salamanca (USAL) em Salamanca, Espanha; professora catedrática da Universidade de Salamanca (USAL), em Salamanca, Espanha.

\section{Marcela Croce}

Doutora em Letras pela Faculdade de Filosofia e Letras da Universidade de Buenos Aires (UBA), em Buenos Aires, Argentina; professora da Universidade de Buenos Aires (UBA), em Buenos Aires, Argentina.

\section{Ana Cristina Steffen}

Mestra em Letras pela Pontifícia Universidade Católica do Rio Grande do Sul (PUCRS), em Porto Alegre, RS, Brasil; doutoranda em Letras na Pontificia Universidade Católica do Rio Grande do Sul (PUCRS), em Porto Alegre, RS, Brasil.

\section{Endereço para correspondência}

Maria Eunice Moreira

Pontificia Universidade Católica do Rio Grande do Sul Avenida Ipiranga, 6681, prédio 8, sala 401.12

Partenon, 90619900

Porto Alegre, RS, Brasil

Paulo Ricardo Kralik Angelini

Pontifícia Universidade Católica do Rio Grande do Sul Avenida Ipiranga, 6681, Prédio 8

Partenon, 90619900

Porto Alegre, RS, Brasil

Ascensión Rivas Hernández

Universidade de Salamanca

Facultad de Filología, Departamento: Lengua Española Plaza de Anaya S/N 37008

Salamanca,Espanha.

\section{Marcela Croce}

Universidad de Buenos Aires

25 de Mayo $221-5^{\circ}$ piso

Código postal C $1002 \mathrm{ABE}$

Ciudad Autónoma de Buenos Aires, Argentina 
Ana Cristina Steffen

Rua Roque Calage, 280/309

Passo da Areia, 91350-090

Porto Alegre, RS, Brasil 